\title{
Effect of Water on the Critical Surface Tension of Coal
}

\author{
Jun Wang \\ CCTEG Shengyang Research Institute, Shenyang 110016, P.R. China; \\ email:cumtblxf@163.com,
}

Keywords: Contact angle, Coal, Wetting, Critical surface tension

Abstract. In order to improve the effect of water injection and dust prevention in coal seam, the wetting process with water in coal was described in this paper. The coal surface tensions with six different aqueous solutions were measured and the contact angle of coal samples from Zhaozhuang Mine was tested. The critical surface tension of the coal samples studied was calculated using the Zisman method. The research indicates that the surface tension with suds is the lowest among the six different aqueous solutions. The average critical surface tension of coal samples from Zhaozhuang Mine is $17.15 \mathrm{mN} / \mathrm{m}$. The water, which decreases the surface tension to below $17.15 \mathrm{mN} / \mathrm{m}$, can make the coal fully wetted and fully expanded. For the water which makes the surface tension higher than $17.15 \mathrm{mN} / \mathrm{m}$, the surface tension approaches this value and the wetting effect is better. The critical surface tension could be applied to evaluate the effect of the coal wetting with mine water.

\section{Introduction}

Coal seam water infusion is an important technique for preventing various hazards. The dust generation can be reduced during mining, and pneumoconiosis, silicosis occupational disease, burst caused by dust can be effectively prevented after wetting coal. Coal seam water infusion can stop the occurrence of coal and gas outburst, rock burst disaster because it can reduce strength and elastic modulus of coal and increase plasticity. Stress is distributed evenly and concentration of high stress is decreased. In addition, coal seam water infusion can improve production, efficiency and accelerate the speed of mining through softening the hard coal, and hinder coal spontaneous combustion. The degree of water wetting coal depends mainly on the nature of water and coal according to the theory of seepage and surface physical chemistry.

Literature[1] showed that the interaction between water and coal was wetting effect and water adsorption in coal. The chemical property within coal can't be changed in the process of coal seam water infusion. The main parameters of ability of water wetting coal are the surface tension and contact angle of coal. Literatures[2-4] showed that the ability of water wetting coal can be increased using magnetized water to reduce the surface tension and contact angle of coal. The surface tension of the aqueous solution of different types and contact angle of coal was studied and the critical surface tension was calculated in this paper. It can provide guidance for improving the effect of coal seam injection.

\section{Wetting process on coal surface}

The surface tension of water is Gibbs free energy on the unit area of water. The smaller surface tension is, the wetting property is better. According to the model of physical layer interface, the surface layer of water has the tendency of spontaneous contraction of surface area because any material surface tension is always positive. But the interface layer of water maybe not have a tendency of spontaneous 
contraction of the interfacial area because the value of interfacial tension of any material is not always greater than zero. The value of interfacial tension should be less than zero when the surface of external force is bigger than the surface of internal force. It makes the interface layer of water have the tendency of expanding its spontaneous interfacial area. Therefore, positive and negative direction of two kinds of interfacial tension should be opposite in Fig.1. The surface force of wetting water system using the traditional way is shown in Fig.1.

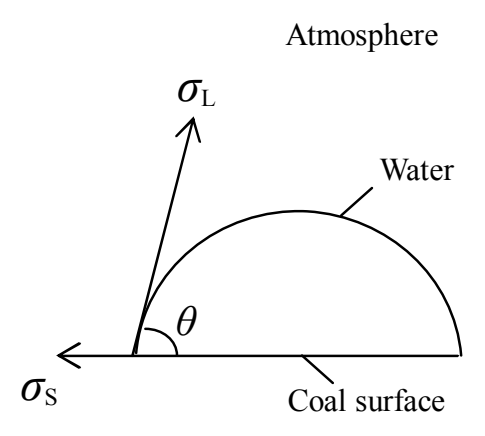

(a) Coal is wetted by water

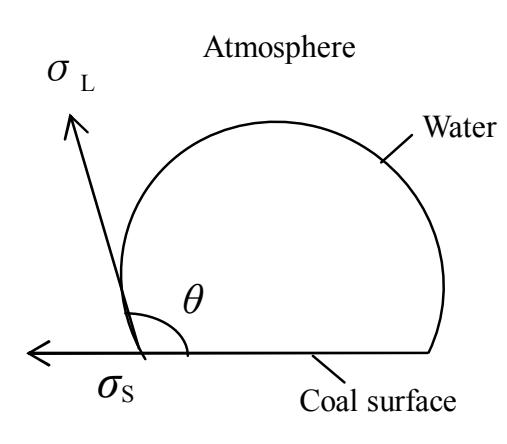

(b) Coal can not be wetted

Fig.1 The surface force system of wetting system

Water has two kinds of interfaces, water-air and water-coal. Therefore, there are two kinds of surface tension on coal surface. When water wets coal, the surface tension $\left(\sigma_{\mathrm{L}}\right)$ will shrink water surface area in aqueous phase, and interfacial tension $\left(\sigma_{\mathrm{S}}\right)$ between water and coal will expand the interface of water. So there must be a mechanical equilibrium state between these two kinds of tensions at some points because drop shape is in a stable equilibrium state. The balanced formula is shown as followed which is also the wetting equation of interface layer model of physical interface.

$$
\sigma_{\mathrm{S}}+\sigma_{\mathrm{L}} \cos \theta=0
$$

Where $\theta$ is contact angle between water and coal. It is the angle between solid-liquid interface and liquid-gas interface by liquid at the junction of solid, liquid, gas phase. The coal can be wetted if $\theta<$ $90^{\circ}$. The smaller $\theta$ is, the bigger capillary force is under the same surface tension coefficient of water. Its ability of wetting increases because of increased water power. The coal can't be wetted if $\theta>90^{\circ}$. The bigger $\theta$ is, the smaller ability of wetting is.

According to the wetting equation of interface layer model of physical interface, when the surface tension $\left(\sigma_{\mathrm{L}}\right)$ reduces, the contact angle $(\theta)$ will reduce to build a new balanced state so that water can wet coal better. Therefore, the wetting ability of water on coal can be presented by surface tension and contact angle. The smaller surface tension and contact angle are, the stronger wetting ability is.

\section{Experimental work}

\section{Coal sample and solution sample preparation}

To study the water adsorption of Chengzhuang coal, some representative coal samples were taken in the 5212 working. Coal samples were made into sheets according to the requirement. It should be polished by sandpaper to make its surface smooth. The water samples include mine water, tap water, pure water, distilled water, soapy water and magnetized water which magnetizing pure water in magnetic field under $1300 \mathrm{mT}$ after $10 \mathrm{~min}$. 


\section{Experimental procedure}

Different kinds of water under room temperature were tested using JZYW-200B (Fig. 2) interfacial tension tester. The platinum ring is immersed in water at a certain position. The core of the differential transformer increases with the decrease of platinum ring and it makes coil induces of the differential transformer inductive a certain voltage. In this way, the deformation of stretched film was converted into voltage, and it can be converted into corresponding tension value through computer and displayed automatically. The tension value increases gradually with stretching film. The maximum value recorded was the real-time tension of water when the film breaks. Six different kinds of contact angle were tested using $\mathrm{JY}-\mathrm{PHb}$ (Fig.3).

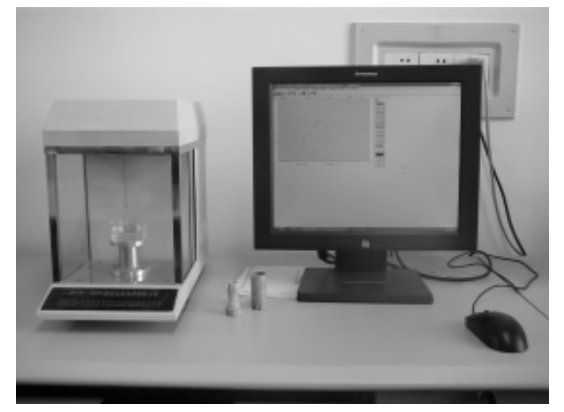

Fig.2 JZYW - 200B Interfacial tension tester

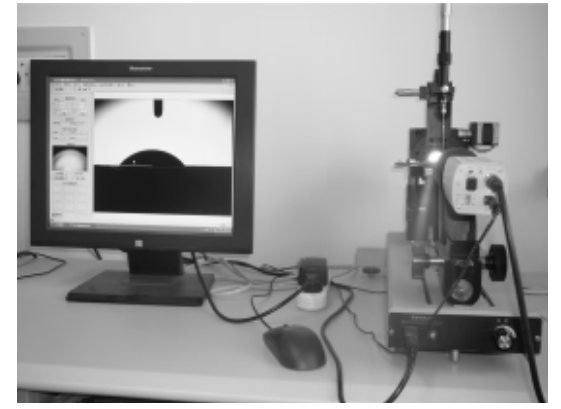

Fig.3 JY - PHb Contact angle measurement

\section{Results and discussion}

The surface tensions of six different kinds of water were tested 4 times under room temperature. Results were shown in Fig. 4. Four different locations of every contact angle between water and coal were tested. The results of different locations were different because of different flatness and roughness. The results were shown in Table 1. Surface tension of mine water close to tap water's, and surface tension of pure water close to distilled water's. Because the main component of mine water and tap water, pure water and distilled water were similar. The Hydrogen bond of magnetized water molecules chains (group) distorted and broke and then the equilibrium distance between molecules became large and the gravitational constant became small. So water molecules were activated and surface tension of magnetized water reduced[5]. Soap is a surfactant. Surfactant reduced its surface tension coefficient through reducing free energy of liquid surface[6]. Therefore, surface tensions of soapy water and magnetized water were low and so does contact angle.

Table 1 Results of contact angles

\begin{tabular}{ccccc}
\hline \multirow{2}{*}{ Solution } & \multicolumn{4}{c}{ Contact angles at different positions $\left({ }^{\circ} \mathrm{C}\right)$} \\
\cline { 2 - 5 } & Position 1 & Position 2 & Position 3 & Position 4 \\
\hline Mine water & 71.9 & 65.4 & 66.0 & 66.8 \\
Tap water & 68.3 & 66.7 & 73.3 & 65.3 \\
Pure water & 69.6 & 68.7 & 66.4 & 68.1 \\
Distilled water & 61.7 & 61.6 & 59.5 & 56.9 \\
Soapy water & 40.9 & 46.9 & 40.6 & 52.9 \\
Magnetized & 55.2 & 60.7 & 48.8 & 48.2 \\
water & & & & \\
\hline
\end{tabular}


Generally, $0.001 \mathrm{~J} / \mathrm{m}^{2}$ is the boundary. The surface energy of high-energy surface is higher than this value, but the surface energy of low-energy surface is lower than this value. In order to analyze the wetting ability of solid surface, critical surface tension was used. According to preceding analysis, surface structure of coal has an important influence on coal ability of adsorbing water. The more uneven surface structure of coal is, the more dangling bonds are, the higher polarity is, the higher surface energy is, the higher ability of adsorbing water is. So, there are many factors influencing ability of adsorbing water such as surface property of coal, temperature, concentration of the surfactant contained in the water. How to measure the wetting ability properties of coal surface. The critical surface tension is introduced in this assessment. Literature[7,8] tested some contact angles between different homologous of this liquid with different surface tension and the same surface of solid. Mapping $\sigma_{\mathrm{L}}$ by $\cos \theta$. A straight line can be gotten for homologous of this liquid. A narrow band, straight line can be gotten for non -homologous liquid. The expression is followed:

$$
\cos \theta=a \sigma_{\mathrm{L}}+b
$$

Where $a$ and $b$ are coefficient related to coal sample and testing position.

The numerical value of the surface of the solid can be gotten when $\cos \theta$ of straight or narrow line was extrapolated to 1 . This value was named critical surface tension $\left(\gamma_{c}\right)$ of liquid for solid wetting.

$$
\gamma_{\mathrm{c}}=(1-b) / a
$$

The homologous of this liquid whose surface tension is less than $\gamma_{c}$ can spread on the surface of the solid with zero contact angle. The fitting situation between $\cos \theta$ of every location and $\sigma_{L}$ of liquid surface tension was shown in Fig.3.

The critical surface tensions of different locations of coal sample are different as shown in Fig.4. The arithmetic mean value of critical surface tension is $17.15 \mathrm{mN} / \mathrm{m}$. The water can fully wet and spread when its surface tension is lower than $17.15 \mathrm{mN} / \mathrm{m}$. When the surface tension is larger than $17.15 \mathrm{mN} / \mathrm{m}$, the closer surface tension value is, the better wetting effect is, the more conducive of coal seam water injection is. The critical surface tension calculation can guide coal seam water injection. The surface tension and its contact angle of various aqueous solutions can be tested in laboratory and obtaining critical surface tension and evaluating wetting ability of coal before coal seam water injection.

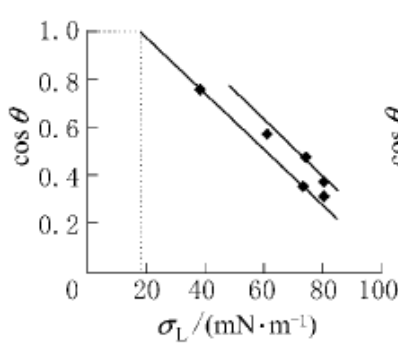

(a) Position 1

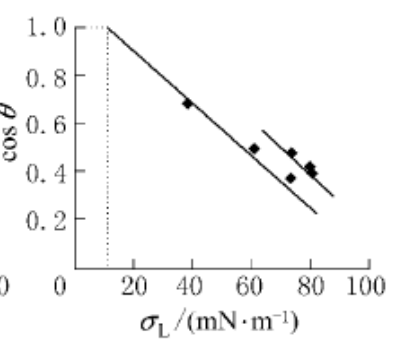

(b) Position 2

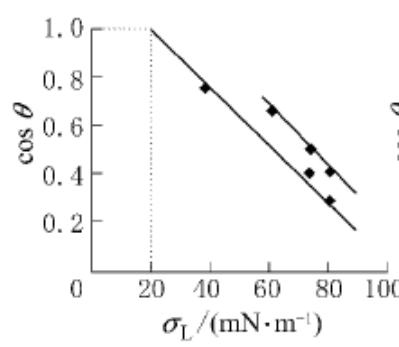

(c) Position 3

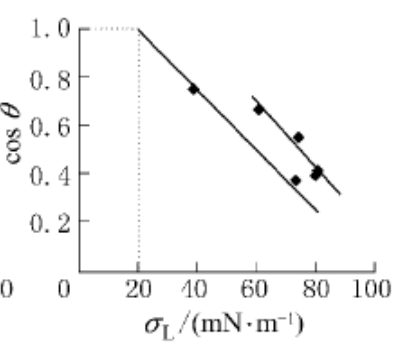

(d) Position 4

Fig.4 Critical surface tension of wetted coal

\section{Summary}

1) The wetting ability of water to coal can be presented by surface tension and size of contact angle with coal. The smaller surface tension and contact angle of coal, the stronger wetting ability of water to coal is. 
2) The critical surface tension of Chengzhuang coal sample is $17.15 \mathrm{mN} / \mathrm{m}$. The water can fully wet and spread when its surface tension is lower than $17.15 \mathrm{mN} / \mathrm{m}$. When the surface tension is bigger than $17.15 \mathrm{mN} / \mathrm{m}$, the closer surface tension value is, the better wetting effect is.

3) The wetting degree of coal surface can be evaluated by critical surface tension, which can guide coal seam water infusion.

\section{References}

[1] B.S. Nie, X.Q. He, E.Y. Wang, Micro-mechanism of coal adsorbing water. Journal of China University of Mining \& Technology, 33(2004):379-383.

[2] B.S. Nie, X.Q. He, Z.H. Feng, Application of magnetized water in coal seam water infusion. Journal of Liaoning Technical University (Natural Science),26(2007):1-3.

[3] Y.J. Cheng, A. Zhong, Z.Q. Chen. Study of adding surfactant to seam water injection. Safety in coal mines, 37(2006):9-12.

[4] Z.H. Yin. The foundational research on water infusion for longwall top coal caving face in para-anthracite seam. Tai Yuan: Taiyuan University of Technology,2006, Phd.

[5] Z.B. Zhao. Physicochemical properties of magnetized water and coal seam injection mechanism. Journal of Liaoning Technical University (Natural Science),27(2008):192-194.

[6] W.H. Ren, Z.Q. Lin, D.L. Peng. On the relationship between the liquid surface tension and the temperature and the concentration. Journal of Hunan Agricultural University (Natural Sciences),30(2004):77-79.

[7] W.A. Zisman. Relation of the equilibrium contact angle to liquidand solid constitution . contact angle, wettability and adhesion. Washington D C: Chemistry Press, 1964:1-51.

[8] M.K. Bernett, W.A. Zisman. Effect of adsorbed water on wetting properties of borosilicate glass, quartz, and sapphire .Journal of Colloid and Interface Science, 29 (1969) : 413-43. 